\title{
Lecionar e pesquisar na educação básica: a atividade investigativa como caminho formativo para professores de português
}

Teaching and researching in basic education: the investigative activity as a training path for Portuguese teachers

Enseñanza e investigación en la educación básica: actividad de investigación como camino para la formación de profesores de portugués

GABRIELA LINS FALCÃO Đa

LIVIA SUASSUNA (iD $\mathrm{b}$

\section{Resumo}

Com o presente artigo, objetivamos contribuir para a discussão acerca do desenvolvimento de pesquisa pelo professor de português no âmbito da educação básica brasileira. A partir da noção de professor pesquisador e da análise dos dispositivos legais que normatizam a profissão docente no Brasil, o tema é tratado com base na articulação de estudos desenvolvidos nas áreas da formação de professores (ANDRÉ, 2001; CONTRERAS, 2002; DINIZ-PEREIRA e ZEICHNER, 2011; IMBERNON, 2016; GATTI, 2017 LÜDKE, 2000 e 2001 PIMENTA, 2012; TARDIF e MOSCOSO, 2018) e do ensino de língua (ANTUNES, 2003 e 2007; DORNELLA, 2007;

\footnotetext{
a Instituto Federal de Pernambuco (Ifpe), Recife, Pe, Brasil. Mestre em educação, e-mail: gabrielafalcao@recife.ifpe.edu.br

${ }^{\mathrm{b}}$ Universidade Federal De Pernambuco (Ufpe), Recife, PE, Brasil. Doutora em linguística, e-mail: liviasuassuna60@gmail.com
} 
GERALDI, 1996, 1997 e 2018; ILARI, 1997; PIETRI, 2003; SOARES, 2001). Os achados desta investigação indicam avanços no tocante à abordagem do tema nos diferentes campos de estudo e nas normativas oficiais, mas ressaltam os entraves existentes para a efetivação de propostas dessa natureza, tendo em vista a necessária efetivação das melhorias previstas nas condições de trabalho do professor pesquisador em atividade nesse nível da educação. Por outro lado, reafirmam a prática da pesquisa como caminho possível para a reconfiguração do trabalho docente, no tocante a questões relativas à autonomia desse profissional e a seu reconhecimento como produtor de conhecimento, bem como seu potencial para contribuir com a construção de práticas de ensino inovadoras, em consonância com os estudos linguísticos mais atuais.

Palavras-chave: Professor pesquisador. Formação de professores. Ensino de português.

\section{Abstract}

With the present article, we aim to contribute to the discussion about the development of research by the Portuguese teacher in the scope of Brazilian basic education. Based on the notion of teacher as a researcher and the analysis of the legal dispositions that normalize the teaching profession in Brazil, the subject is treated based on the articulation of studies developed in the areas of teacher training (ANDRÉ, 2001; CONTRERAS, 2002; DINIZ-PEREIRA e ZEICHNER, 2011; IMBERNON, 2016; GATTI, 2017; LÜDKE, 2001 E 2002; PIMENTA, 2012; TARDIF e MOSCOSO, 2018) and language teaching (ANTUNES, 2003 e 2007; DORNELLA, 2007; GERALDI, 1996, 1997 e 2018; ILARI, 1997; PIETRI, 2003; SOARES, 2001). The findings of this research indicate advances in the approach to the subject in different fields of study and official regulations, but highlight the obstacles to the implementation of proposals of this nature, in view of the necessary effectiveness of the improvements foreseen in the working conditions of the teacher researcher at this level of education. On the other hand, they reaffirm the practice of research as a possible way for the reconfiguration of teaching work, regarding issues related to the autonomy of this professional and their recognition as a producer of knowledge, as well as their potential to contribute to the construction of teaching practices innovative, in line with the most current language studies.

Keywords: Research teacher. Teacher training. Portuguese Teaching.

\section{Resumen}

Con este artículo, nos proponemos a contribuir a la discusión sobre el desarrollo de investigación por el profesor de portugués en el ámbito de la educación básica brasileña. A partir de la noción de profesor investigador y del análisis de los dispositivos legales que normatizan la profesión docente en Brasil, el tema es tratado con base en la articulación de estudios desarrollados en las áreas de la formación de profesores (ANDRÉ, 2001; CONTRERAS, 2002; DINIZ-PEREIRA e ZEICHNER, 2011; 
IMBERNON, 2016; GATTI, 2017; LÜDKE, 2001 E 2002; PIMENTA, 2012; TARDIF e MOSCOSO, 2018) y de la enseñanza de la lengua (ANTUNES, 2003 e 2007; DORNELLA, 2007; GERALDI, 1996, 1997 e 2018; ILARI, 1997; PIETRI, 2003; SOARES, 2001). Los resultados de esta investigación indican avances en el abordaje del tema en los diferentes campos de estudio y en las normativas oficiales, pero resaltan los obstáculos existentes para la efectividad de propuestas de esa naturaleza, teniendo en vista la necesaria efectivización de las mejoras previstas en las condiciones de trabajo del profesor investigador en actividad en ese nivel educacional. Por otro lado, reafirman la práctica de la investigación como camino posible para la reconfiguración del trabajo docente, en lo que se refiere a cuestiones relativas a la autonomía de ese profesional y a su reconocimiento como productor de conocimiento, así como su potencial para contribuir con la construcción de prácticas de enseñanza innovadoras, en consonancia con los estudios lingüísticos más actuales.

Palabras clave: Profesor investigador. Formación de profesores. Enseñanza del portugués.

\section{Introdução}

Parece generalizada a visão de que seria prescindível à atividade do professor na educação básica o trabalho contínuo com pesquisa. Existem autores que reverberam esse discurso, apontando as dificuldades existentes no ambiente escolar para o desenvolvimento dessa atividade, ou que sustentam a separação entre ensino e pesquisa pelas características conceituais, sociais e até mesmo espaciais que as constituem.

Concordamos com Lüdke (2002, p. 51), no entanto, quando esta afirma não ter dúvidas quanto à necessidade de "introduzir o futuro professor no universo da pesquisa, em sua formação inicial e continuada, garantindo assim a possibilidade de exercício do magistério de maneira muito mais crítica e autônoma". Em consonância com esse posicionamento teórico, Lüdke \& André (1986, p. 2), a partir dos resultados de suas pesquisas com docentes da educação básica, ressaltam a necessidade e a importância de superar a visão da atividade investigativa como "privilégio de alguns seres dotados de poderes especiais".

Buscando discutir as atuais possibilidades e os entraves existentes na integração e na articulação da atividade investigativa com a docência, e reconhecendo seu potencial formativo e ressignificador do trabalho docente desde a 
educação básica, construímos este artigo, resultado de uma reflexão embasada nos estudos de autores das áreas de formação docente e de ensino de língua portuguesa.

Faz-se fundamental, no entanto, antes de tecer nossas considerações sobre o tema, elucidar o conceito de pesquisa do qual partimos, haja vista a complexidade do termo e a multiplicidade de usos e de sentidos a ele atribuídos, além de distinguir as noções referentes a professor reflexivo, crítico reflexivo e pesquisador, diferenciando-os e situando-os no interior do debate em torno da formação de docentes no Brasil. Em seguida, discorreremos sobre como o assunto vem sendo tratado em diferentes dispositivos legais brasileiros na atualidade, buscando dialogar com as mudanças no ensino e as possíveis contribuições da prática de pesquisa como alternativa transformadora da atuação profissional do professor de língua portuguesa.

\section{O professor reflexivo, crítico reflexivo e pesquisador: semelhanças e diferenças na construção da identidade docente na educação básica}

Preparar educadores capazes de exercer ativa e criticamente a docência frente às atuais e aceleradas transformações das diferentes esferas sociais mostra-se um dos mais importantes desafios da educação mundial (ANDRÉ, 2001; DINIZ-PEREIRA e ZEICHNER, 2011). Concordamos com Perrenoud (2000), quando este afirma que a preocupação com a formação de professores que não apenas acompanhem as mudanças nos estágios de desenvolvimento das ciências, das tecnologias e da sociedade em geral, mas que se situem como sujeitos ativos diante da complexidade organizacional dessas múltiplas realidades precisa estar presente nos ambientes de formação inicial e continuada dos profissionais da educação.

Os estudos de Donald Schön relacionados às reformas curriculares nos cursos de formação de profissionais, especialmente a partir dos anos 1990, e à necessidade de consolidar essa formação com base em uma epistemologia da prática foram incorporados à educação brasileira como alternativa na busca por romper com a racionalidade técnica determinante nos cursos de formação até então. Com isso, segundo Pimenta (2012, p. 23), abriram-se perspectivas para “a valorização da 
pesquisa na ação dos profissionais, colocando as bases para o que se convencionou denominar o professor pesquisador de sua prática”.

Alinhamo-nos com Perrenoud (2001), quando este afirma que a capacidade de refletir em e sobre a ação é pré-requisito para o exercício da autonomia e da responsabilidade de um profissional. É a partir dessa ação reflexiva, portanto, que o docente assume a capacidade de se manter em desenvolvimento permanente e de afirmar sua autonomia na defesa de seus direitos políticos e sociais, por exemplo, bem como na seleção de objetos e objetivos de ensino, de estratégias didáticas, de instrumentos de avaliação, enfim, na organização de seu trabalho dentro e fora da sala de aula. Uma atuação docente com base em uma perspectiva tradicional e reprodutora tem raízes, muitas vezes, em uma formação profissional tecnicista, especialmente em sua fase inicial, realidade que dificulta o acesso desses profissionais a dispositivos de efetiva construção dos saberes que lecionam e de interpretação dos diferentes contextos sociais em que se inserem.

Perrenoud (2001, p. 50) assume que os docentes precisam estar em constante processo de reflexão e enumera algumas razões para justificar a importância de os professores refletirem sobre o fazer docente, dentre elas a possibilidade de compensar a superficialidade da formação profissional e de buscar contribuições para a profissionalização. A formação inicial, segundo o autor, é sempre incompleta, pois seria impossível antever todas as situações que o docente teria de vivenciar no exercício de sua profissão. Assim, a atividade de reflexão permitiria uma ação consciente quando fosse "necessário aprender seu ofício na prática cotidiana" (PERRENOUD, 2001, p. 50). Por outro lado, também contribuiria para a profissionalização do trabalho de professor, visto que é condição necessária para o desenvolvimento da autonomia e da ação reivindicatória, contribuindo para a constituição de uma identidade profissional docente.

A despeito da relevância de pensar a prática docente a partir de uma perspectiva reflexiva, concordamos com Tardif e Moscoso (2018), quando estes alertam para os riscos da banalização e do uso genérico dessa noção, evidenciados na massificação do conceito. Para os autores, a reflexão não deve ser acrescida ao bojo dos referenciais de competências requeridas do professor, tampouco pode ser encarada como processo metódico, analítico e subjetivo, sob 
pena de resultar em "uma disposição vazia e universal das práticas e da mobilização de competências" (p. 402).

Ao abordarem o possível reducionismo do saber profissional ao lócus da experiência, presente na perspectiva do professor reflexivo, os autores ampliam a noção proposta por Schön (1992) e reverberada por outros estudos decorrentes de suas ideias no campo da formação docente, afirmando que a reflexividade deve ser entendida "como resultado das transformações que caracterizam nossas sociedades atuais” (p. 402), e destacando a intersubjetividade, a exteriorização, a interação e a atribuição de sentido ao fazer profissional como suas características fundamentais. Para Tardif e Moscoso (2018), portanto, a reflexão docente não é uma prática individual; ao contrário, trata-se de

uma prática profissional vivida e compartilhada com outros, uma prática que precisa ser reconhecida pelos outros se quiser aspirar a se realizar com eles. Em outras palavras, o professor não só deve refletir sobre sua prática, mas também sobre a reflexão dos outros, sobre as práticas dos outros, sobre o modo como os outros recebem sua prática e refletem a partir dela, de maneira simultânea (TARDIF; MOSCOSO, 2018, p. 406).

Tal noção reconfigura as dimensões reflexivas e interativas do fazer docente, e abre caminho para o uso dessa noção em pesquisas desenvolvidas com e pelos professores.

Também sobre as contradições presentes na massificação e na apropriação histórica do conceito de professor reflexivo, e sobre os limites que este carrega quanto à ação individual do docente e ao espaço de ação e de reflexão circunscrito à sala de aula e em sua própria prática, Contreras (2002) revela a necessidade de considerar o docente como um intelectual crítico e reflexivo, ampliando, com isso, o reconhecimento de sua identidade e atuação profissional.

Pimenta (2012, p. 51), por sua vez, ratifica as críticas ao conceito de professor reflexivo, elencando alguns problemas, encontrados por meio de análises teóricas e empíricas, dessa perspectiva, tais como “o individualismo da reflexão, a ausência de critérios externos potenciadores de uma reflexão crítica, a excessiva (e mesmo exclusiva) ênfase nas práticas, a inviabilidade da investigação nos espaços escolares e a restrição desta nesse contexto". Concordamos com a autora também 
quando esta afirma, em concordância com Contreras (2002) e Tardif e Moscoso (2018), que a passagem da noção de professor reflexivo para a de intelectual crítico reflexivo contempla de forma mais efetiva o caráter público e ético da reflexão.

Além disso, Pimenta (2015, p. 51) destaca a relevância da construção de conhecimentos por parte dos professores "a partir da análise crítica (teórica) das práticas e da ressignificação das teorias a partir dos conhecimentos da prática (práxis)", rompendo com a dimensão exclusiva da epistemologia da prática contida no ideal de professor reflexivo. A autora aponta, ainda, os benefícios advindos da inclusão da pesquisa no ambiente escolar como parte integrante da jornada de trabalho dos profissionais da escola, inclusive em colaboração com as instituições universitárias, a fim de garantir o desenvolvimento profissional dos professores.

Ao ampliarmos a concepção de docente, reconhecendo-o como intelectual crítico e reflexivo, não assumimos apenas uma mudança terminológica, mas, a partir das características defendidas por Contreras (2002) e Tardif e Moscoso (2018), reafirmamos as múltiplas dimensões que constituem esse profissional. Ratificamos, pois, a necessidade do entendimento do professor como um profissional capaz de pensar e de articular diferentes saberes, incluindo os saberes experienciais, científicos e pedagógicos, na construção e na proposição de transformações necessárias às práticas e aos contextos intra e extraescolar. Professores são, pois, sujeitos compromissados local e globalmente.

Quanto ao uso da expressão professor pesquisador, concordamos com Lüdke (2001), que afirma que "nem todo professor, por ser reflexivo, é também pesquisador, embora a recíproca seja, por força, verdadeira” (p. 31). Defender um professor crítico reflexivo, por sua vez, não significa o mesmo que defender o professor como pesquisador, apesar de estas não serem noções contraditórias; tampouco é possível afirmar que um pesquisador seja, automaticamente e por si, um professor crítico reflexivo.

Com base nessa distinção, reconhecemos a existência de limites da atividade de pesquisa no que tange ao oferecimento de respostas suficientes para os pontos críticos existentes no desempenho do trabalho docente; todavia, pontuamos o potencial das práticas investigativas no sentido de possibilitar ao professor o entendimento dos instrumentos e do processo de elaboração e de construção do 
conhecimento. Tal compreensão apresenta-se como uma alternativa para contribuir com a formação desse profissional, para o entendimento da multiplicidade dos saberes que o constituem e para seu próprio reconhecimento como sujeito crítico reflexivo e agente construtor de conhecimentos. Acerta Lüdke (2001), portanto, quando afirma que não é apenas como acontecimento cognitivo que a pesquisa pode contribuir para o desenvolvimento profissional, já que ela tem um importante papel na construção e na aquisição de novos saberes por parte do pesquisador, e se configura, em si mesma, como acontecimento social.

Nessa perspectiva, a importância da aquisição de uma postura investigativa pelo docente reside na possibilidade que esta tem de contribuir para o surgimento de um olhar crítico e reflexivo sobre a prática e para além dela, permitindo ao docente uma constante reformulação de conhecimentos teórico-metodológicos, por exemplo, acerca da ação educativa e de seu próprio objeto de ensino.

Concordamos, pois, com Schnetzler (1998, p. 08), que aponta para a necessidade de a pesquisa educacional ser considerada constitutiva da própria atividade docente, uma vez entendida "como condição de desenvolvimento profissional do professor e de melhoria da sua prática pedagógica". Dessa forma, o trabalho com pesquisa é aqui considerado como importante mecanismo para criar um "espaço de resistência, de crédito e de mérito" para esse profissional.

\section{Concepção de pesquisa docente e o que dizem os dispositivos legais}

Apesar de pouco referenciada pela Lei de Diretrizes e Bases da Educação Nacional, e inicialmente apenas indicada com o acréscimo do dispositivo legal $\mathrm{n}^{\circ}$ 12.014 de 2009, o qual evoca a necessidade de o processo de formação dos profissionais da educação propiciar o conhecimento dos fundamentos científicos e sociais de suas competências de trabalho, a relação do professor com a pesquisa surge com evidência em 2002, com a publicação das Diretrizes Curriculares Nacionais para a Formação de Professores da Educação Básica, a qual aborda, em vários pontos, a necessidade e a importância da formação do docente para a pesquisa. O disposto nesse documento é acrescido de avanços significativos com a 
atual Resolução CNE/CP n ${ }^{\circ}$ 2, de 1 julho de 2015, que define as Diretrizes Curriculares Nacionais para a formação inicial em nível superior (cursos de licenciatura, cursos de formação pedagógica para graduados e cursos de segunda licenciatura) e para a formação continuada.

Logo em seu artigo segundo, no inciso IV, as Diretrizes Curriculares Nacionais para a Formação de Professores da Educação Básica, publicadas em 2002, consideram a prática de pesquisa como inerente à atividade docente e, portanto, fundamental à sua formação. O preparo para o exercício da docência deve considerar, segundo esse dispositivo legal, como um de seus princípios norteadores,

III - a pesquisa, com foco no processo de ensino e de aprendizagem, uma vez que ensinar requer tanto dispor de conhecimentos e mobilizá-los para a ação, como compreender o processo de construção do conhecimento (BRASIL/ CNE/CP $n^{\circ} 1, \mathrm{DE}$ 18 DE FEVEREIRO DE 2002, Art. 3ㅇ, inciso III).

A importância de reconhecer a prática investigativa como fundamental na formação docente também aparece no inciso $\mathrm{V}$ dessa mesma resolução, que define que os cursos de formação de professores devem, em seu projeto pedagógico, considerar "as competências referentes ao conhecimento de processos de investigação que possibilitem o aperfeiçoamento da prática pedagógica". Apesar da aparente sintonia com as atuais discussões desenvolvidas na área de educação e linguagem quanto à formação docente, André (2001) afirma que o texto oficial apresenta dúvidas quanto à questão da concepção de pesquisa e da limitação de seu objeto. A autora diz que

se o documento tinha a boa intenção de valorizar a pesquisa na formação docente, acabou provocando uma reação oposta ao reduzir o papel da ciência na formação docente, criando uma dicotomia entre pesquisa acadêmica e pesquisa do professor e vedando a possibilidade de que o professor possa fazer pesquisa acadêmica ou científica (ANDRÉ, 2001, p. 67).

Concordamos com o texto acima cito, quando nele se reconhecem limitações da resolução de 2002 quanto à concepção de pesquisa a ser desenvolvida pelos docentes da educação básica, tendo em vista a oposição criada entre esta e a pesquisa de natureza acadêmica ou científica. Consideramos fundamental a superação dessa dicotomia na trajetória formativa docente, tendo em vista que o 
trabalho investigativo pode servir não apenas como fonte de reflexão sobre a prática e sobre o exercício da docência, mas como instrumento para conhecer o processo de produção do próprio conhecimento a ser ensinado em sala de aula, o que nos faz pontuar algumas questões sobre a concepção de pesquisa aqui defendida.

Assumimos, então, a definição de pesquisa levantada por Beillerot (2001), para quem o termo pesquisa é uma atividade que deve obedecer a certos critérios.

Um primeiro conjunto desses critérios engloba a produção de conhecimentos novos, um encaminhamento rigoroso e a comunicação de resultados. Em termos do primeiro critério, Beillerot afirma que um conhecimento é considerado novo se "é admitido como tal pela comunidade mais autorizada para sustentar um julgamento desse tipo" (p. 74). Assim, a busca por um saber já conhecido pelo "conjunto das comunidades", mesmo que produza algo "novo" para o sujeito que o descobre, não constitui pesquisa nessa acepção, como frequentemente ocorre nas atividades em sala de aula. Quanto ao segundo critério, que diz respeito ao encaminhamento da pesquisa, o autor afirma que o rigor metodológico deve ser tal, que permita sua reconstrução e reafirme a legitimidade da descoberta, devendo, ainda, ser admitido pelo grupo de referência. A terceira e última das condições mínimas necessárias a uma pesquisa diz respeito a sua divulgação. Assim, "não haveria pesquisa caso não houvesse o desejo de comunicar, de uma maneira ou de outra, os resultados daquilo que se encontrou" (p. 75); a divulgação permite o compartilhamento do conhecimento para sua verificação, apreciação crítica e acumulação.

O segundo grande conjunto de critérios contempla: a contribuição da pesquisa para uma postura crítica e reflexiva sobre suas fontes, métodos e modos de trabalho (critério n. 04); a sistematização da coleta dos dados (critério n. 05); (c) as interpretações dos dados construídas a partir de confrontos com teorias reconhecidas, contribuindo para sua maior legitimação (critério n. 06).

Esses três últimos critérios são capazes de distinguir uma pesquisa minima, com apenas três critérios observáveis, de uma pesquisa de segundo grau, com obediência a 4, 5 ou 6 critérios.

Apesar de não existir uma definição clara para o trabalho de investigação desenvolvido pelos docentes nas escolas de nível básico, os critérios acima 
elencados nos ajudam a realizar uma classificação geral de pesquisa e apontam caminhos importantes para pensar na prática investigativa docente, conforme propomos deste estudo. No entanto, como também afirma Lüdke (2001), reconhecemos que qualquer grupo de critérios apresenta limitações, mas sua ausência é ainda mais prejudicial para a compreensão dos dados e para o desenvolvimento de uma pesquisa.

Na Resolução CNE/CP nº 2, de 1 julho de 2015, a qual define as Diretrizes Curriculares Nacionais para a formação inicial em nível superior (cursos de licenciatura, cursos de formação pedagógica para graduados e cursos de segunda licenciatura) e para a formação continuada, tal dicotomia entre pesquisa de natureza acadêmica ou científica e pesquisa do professor parece estar superada. Em diferentes momentos a pesquisa científica surge como parte do próprio fazer docente, firmemente defendida e estimulada desde a formação inicial e ratificada pelas propostas de uma formação continuada, que inclui também cursos de pósgraduação stricto sensu.

Vejamos o que diz o documento, em seu Art. $2^{\circ}$, quando da definição de seu escopo e da própria atividade docente:

$\S 1^{\circ}$ Compreende-se a docência como ação educativa e como processo pedagógico intencional e metódico, envolvendo conhecimentos específicos, interdisciplinares e pedagógicos, conceitos, princípios e objetivos da formação que se desenvolvem na construção e apropriação dos valores éticos, linguísticos, estéticos e políticos do conhecimento inerentes à sólida formação científica e cultural do ensinar/aprender, à socialização e construção de conhecimentos e sua inovação, em diálogo constante entre diferentes visões de mundo (BRASIL, 2015, p. 3).

A articulação entre ensino e pesquisa, e entre os diferentes níveis da educação nacional, é reafirmada ao longo de todo o documento, como um dos princípios norteadores da Formação de Profissionais do Magistério da Educação Básica. A prática investigativa, a construção do conhecimento e a inovação surgem, então, como parte da ação educativa e do processo pedagógico, segundo a resolução, "contribuindo para ampliar a visão e a atuação desse profissional", favorecendo a compreensão ampla e contextualizada da educação escolar e "visando assegurar a produção e difusão de conhecimentos de determinada área” (BRASIL, 2015, p. 3). 
O avanço, na referida resolução, quanto à adoção da pesquisa como parte fundamental à formação dos profissionais do magistério e, portanto, trazendo a identidade de pesquisador no perfil de egresso pretendido desde os cursos iniciais, aparece em destaque no Art. $5^{\circ}$ do referido documento, o qual afirma:

Art. $5^{\circ}$ A formação de profissionais do magistério deve assegurar a base comum nacional, pautada pela concepção de educação como processo emancipatório e permanente, bem como pelo reconhecimento da especificidade do trabalho docente, que conduz à práxis como expressão da articulação entre teoria e prática e à exigência de que se leve em conta a realidade dos ambientes das instituições educativas da educação básica e da profissão, para que se possa conduzir o(a) egresso(a):

I - à integração e interdisciplinaridade curricular, dando significado e relevância aos conhecimentos e vivência da realidade social e cultural [...];

II - à construção do conhecimento, valorizando a pesquisa e a extensão como princípios pedagógicos essenciais ao exercício e aprimoramento do profissional do magistério e ao aperfeiçoamento da prática educativa;

III - ao acesso às fontes nacionais e internacionais de pesquisa, ao material de apoio pedagógico de qualidade, ao tempo de estudo e produção acadêmico-profissional, viabilizando os programas de fomento à pesquisa sobre a educação básica;

IV - às dinâmicas pedagógicas que contribuam para o exercício profissional e o desenvolvimento do profissional do magistério por meio de visão ampla do processo formativo, seus diferentes ritmos, tempos e espaços, em face das dimensões psicossociais, histórico-culturais, afetivas, relacionais e interativas que permeiam a ação pedagógica, possibilitando as condições para o exercício do pensamento crítico, a resolução de problemas, o trabalho coletivo e interdisciplinar, a criatividade, a inovação, a liderança e a autonomia;

$V$ - à elaboração de processos de formação do docente em consonância com as mudanças educacionais e sociais, acompanhando as transformações gnosiológicas e epistemológicas do conhecimento [...] (BRASIL, 2015, p. 06, grifo nosso).

A atividade investigativa é assumida, como podemos ver, como princípio pedagógico, como fonte e como procedimento, alçada ao patamar de parte constituinte do exercício profissional e entendida como meio para seu aperfeiçoamento. Mais adiante, em seu Art. $7^{\circ}$, o documento reafirma tal postura, ao vincular o projeto pedagógico e o percurso formativo da formação inicial e continuada a trajetórias que permitam, ao egresso: "a pesquisa, a análise e a aplicação dos resultados de investigações de interesse da área educacional e 
específica", bem como a leitura e a discussão de referenciais teóricos contemporâneos educacionais e de formação para a compreensão e a apresentação de propostas e dinâmicas didático-pedagógicas, aspecto também caro e necessário à fundamentação do trabalho do pesquisador.

Outro avanço que merece destaque e que dialoga com a proposta deste estudo diz respeito ao reconhecimento da existência de uma postura investigativa e da valorização desta no perfil profissional docente. A capacidade de problematizar, de fazer uso de instrumentos de pesquisa, de buscar caminhos e de realizar proposições para a abordagem de diferentes aspectos e temas da realidade profissional surge como meta a ser atingida e, portanto, reafirma o ideal do professor pesquisador também no nível da educação básica brasileira. Vejamos, sobre isso, o que diz o Art. $8^{\circ}$ da resolução:

Art. $8^{\circ} \mathrm{O}(\mathrm{A})$ egresso(a) dos cursos de formação inicial em nível superior deverá, portanto, estar apto a:

[...] VII - identificar questões e problemas socioculturais e educacionais, com postura investigativa, integrativa e propositiva em face de realidades complexas, a fim de contribuir para a superação de exclusões sociais, étnico-raciais, econômicas, culturais, religiosas, políticas, de gênero, sexuais e outras [...].

$X I$ - realizar pesquisas que proporcionem conhecimento sobre os estudantes e sua realidade sociocultural, sobre processos de ensinar e de aprender, em diferentes meios ambiental-ecológicos, sobre propostas curriculares e sobre organização do trabalho educativo e práticas pedagógicas, entre outros;

XII - utilizar instrumentos de pesquisa adequados para a construção de conhecimentos pedagógicos e científicos, objetivando a reflexão sobre a própria prática e a discussão e disseminação desses conhecimentos [...] (BRASIL, 2015, p. 08, grifo nosso).

Em consonância com o ideal formativo e com o fomento à identidade de professor pesquisador, o texto ainda incentiva, para os cursos de formação inicial, a constituição de núcleos de estudo, a existência de programas de iniciação científica e a realização de eventos científicos para socialização de conhecimentos, o que, sem dúvida, contribuiria para a criação de um contexto favorável a essa perspectiva formativa. Em termos da formação continuada, destaca-se a necessidade, para o professor, "de acompanhar a inovação e o desenvolvimento associados ao conhecimento, à ciência e à tecnologia" (BRASIL, 2015, p. 14), bem como o 
respeito a seu protagonismo e a um "espaço-tempo" que lhe permita refletir criticamente e aperfeiçoar o exercício de sua profissão.

Reconhecemos que as condições de trabalho do professor não podem, sob nenhuma hipótese, ser dissociadas do conjunto dos demais princípios formativos ou do seu perfil profissional, tampouco poderíamos sustentar o ideário da pesquisa na educação básica sem ao mesmo tempo defender uma profunda transformação da realidade hoje vivenciada nas redes de ensino e nas escolas brasileiras. Quanto a esses entraves, a resolução aponta caminhos de melhorias, inclusive, quanto à valorização da carreira e ao dimensionamento da jornada de trabalho dos docentes.

O documento afirma que tal valorização é dimensão constitutiva e constituinte da formação docente inicial e continuada, e indica a necessidade de serem definidas jornadas de trabalho com dedicação exclusiva ou tempo integral, a serem cumpridas em um único estabelecimento de ensino; sugere, ainda, a destinação de $1 / 3$ da carga horária de trabalho a "outras atividades pedagógicas inerentes ao exercício do magistério, tais como: I - preparação de aula, estudos, pesquisa e demais atividades formativas [...]” (BRASIL, 2015, p. 15).

Além dessa relevante proposição, o texto prevê, ainda, a criação, no interior das escolas, de grupos de trabalho e/ou estudos, bem como a vivência de atividades de desenvolvimento profissional, possibilitando, portanto, a criação de um ambiente favorável ao desenvolvimento de pesquisa por parte dos docentes em atuação na educação básica.

Faz-se fundamental destacar a estreita relação entre a Resolução CNE/CP n ${ }^{\circ}$ 2/2015 e a Lei $n^{\circ}$ 13.005/2014, anterior a ela, na qual se institui o Plano Nacional de Educação (PNE) e são consolidadas diretrizes, metas e estratégias para as políticas educacionais brasileiras, para o decênio 2014/2024. No interior de suas 20 metas, encontramos explicitados caminhos para a valorização do professor e de sua formação, bem como para a melhoria das condições de trabalho. Dourado (2016) analisa as metas 16 a 18 do referido documento, as quais tratam diretamente dessas questões:

A Meta 16, formar, em nível de pós-graduação, 50\% dos professores da educação básica até o último ano de vigência deste PNE e garantir a todos/as os/as profissionais da educação básica formação continuada em sua área de atuação [...]. 
A Meta 17 consiste em valorizar os/as profissionais do magistério das redes públicas de educação básica de forma a equiparar seu rendimento médio ao dos/as demais profissionais com escolaridade equivalente, até o final do sexto ano e vigência deste PNE. Esta meta, embora restrita ao segmento docente, é de grande impacto e constitui-se em reivindicação histórica do campo, apresentando estratégias importantes na consecução de uma efetiva política de valorização do profissional do magistério ao articular salário, carreira e condições de trabalho.

A Meta 18, assegurar, no prazo de dois anos, a existência de planos de carreira para os/as profissionais da educação básica e superior pública de todos os sistemas de ensino e, para o plano de carreira dos/as profissionais da educação básica pública, tomar como referência o piso salarial nacional profissional, é fundamental para o setor, a despeito de negligenciar os profissionais do setor privado [...] (DOURADO, 2016, p. 33).

Além de reafirmar, em sua Meta 16, a relevância do incentivo e do fomento à formação, em nível de pós-graduação, dos professores da educação básica, o PNE ratifica o reconhecimento dessa etapa de formação como caminho para o aperfeiçoamento e o desenvolvimento desses profissionais. Além de pontuar como uma das metas a criação, de forma articulada entre os entes federativos, de uma política nacional de formação dos profissionais da educação, e de incluir, no debate e nas ações previstas, questões relativas à valorização, a planos de carreira e às condições de trabalho desses profissionais, o documento representa um marco para a construção de um projeto de educação nacional, tendo em vista seu potencial estratégico articulador, e o interesse na coerência e na organicidade das ações formativas destinadas aos profissionais da educação. As Diretrizes Curriculares Nacionais para a formação inicial em nível superior e para a formação continuada, como vimos, foram instituídas, pois, no bojo de uma série de documentos que visam à formalização de concepções, objetivos e interesses relativos à educação nacional e a seus profissionais.

Concordamos com Gatti (2017, p. 1155), no entanto, quando esta afirma que a efetivação de planos dessa natureza e de suas propostas depende de ações concretas "que propiciem a passagem do dito ao realizado", fazendo-se urgentes, portanto, ações e políticas públicas consequentes para sua materialização, incluídos aí a realização das metas e disposições contidas na Lei $\mathrm{n}^{\circ} 13.005 / 2014$ e o acompanhamento constante de sua efetivação. 
No tocante ao perfil do professor da educação básica como pesquisador, as diretrizes específicas para o curso de Letras (BRASIL/CNE nº. 009/2001), por sua vez, afirmam que tais cursos deverão ter estruturas flexíveis que promovam uma articulação constante entre ensino, pesquisa e extensão, além de articulação direta com a pós-graduação. O mesmo documento, no tocante ao perfil do egresso do curso, afirma ainda que este

deve ser capaz de refletir teoricamente sobre a linguagem, de fazer uso de novas tecnologias e de compreender sua formação profissional como processo contínuo, autônomo e permanente. A pesquisa e a extensão, além do ensino, devem articular-se neste processo (BRASIL/CNE/CP nº 009/2001, p. 30).

A atividade de pesquisa apresenta-se, segundo o documento oficial, como aliada do formando em Letras na construção de seu percurso formativo, devendo contribuir também, como se afirma mais adiante, para a consolidação de uma visão crítica das perspectivas teóricas adotadas nas investigações linguísticas e literárias que fundamentam sua formação profissional. Percebe-se, no entanto, pouca ênfase na formação do professor para uma atuação efetiva em processos de investigação como habilidade necessária ao desenvolvimento da profissão, não se mencionando uma formação direcionada aos procedimentos próprios a essa atividade.

Em consonância com a necessidade de oferecer ao professor a oportunidade de desenvolver pesquisas a partir de métodos considerados científicos, Ilari (1997) chama atenção para a contribuição desse processo na ruptura de uma visão limitada do funcionamento da linguagem. Esse entendimento do autor, apesar de defendido pelas teorias mais recentes sobre formação docente nas diferentes áreas de conhecimento, e presente, mesmo que de forma incipiente, nas Diretrizes Curriculares Nacionais para a Formação de Professores da Educação Básica, não é reforçado no documento específico de formação do profissional de Letras. 


\section{As contribuições da pesquisa para (re)pensar a formação e a atuação docente: transformações e inovação no ensino de português}

Os estudos acerca do ensino de português no Brasil tornaram-se mais recorrentes a partir da década de 1980, após a virada pragmática, e trouxeram algumas reflexões fundamentais — tanto do ponto de vista pedagógico quanto do sociopolítico - para reconfigurar objetos e objetivos das aulas de língua materna (GERALDI, 1997; ANTUNES, 2007; SUASSUNA, 2006). Essas mudanças produziram impactos na própria concepção de língua e, portanto, nos propósitos de seu ensino, resultando na ascensão da reflexão sobre os usos e a interação social como eixos centrais das atividades de linguagem em sala de aula.

Essa transição vivenciada no ensino de língua materna, decorrente, essencialmente, das contribuições da linguística e da virada pragmática (SUASSUNA, 2006; GERALDI, 1997), implicaram uma redefinição no entendimento e no ensino da língua, pressupondo, para sua concretização em sala de aula, uma prática docente pautada na capacidade de ressignificar conceitos, práticas e procedimentos, bem como de compreender o conhecimento em sua característica mais inerente, a incompletude. $O$ texto e seus procedimentos de leitura, de escrita e de análise, por sua vez, foram tornados centrais nas aulas de português, e as produções linguísticas passaram a ser compreendidas para além de suas unidades estritamente gramaticais.

Segundo Pietri (2003) e Dornelles (2007), tal discurso da mudança é protagonizado pela ciência linguística, eixo determinante em diferentes projetos de inovação no ensino de língua portuguesa. A demanda por essa inovação na educação básica tem se afirmado, inclusive, por meio de documentos oficiais (BRASIL, 2012), respaldando-se cientificamente, como afirmam Pietri (2003) e Shavinina (2003), pelo crescimento e divulgação dos achados linguísticos, mas também pelo discurso desenvolvimentista, com base na tecnologia e na modernização, presente nas diferentes partes do globo. 
Em diálogo com essa perspectiva inovadora, Santos (2001) afirma que uma das maiores contribuições da pesquisa para a prática pedagógica é a constituição de uma atitude questionadora, crítica e reflexiva sobre o fazer pedagógico, para além do entendimento dos professores como "consumidores, transmissores e implementadores do conhecimento produzido em outras instâncias" (ANDRÉ, 2001, p. 17).

Para romper com o paradigma reprodutor do ensino de língua, portanto, fazem-se necessárias, dentre outros fatores, duas mudanças essenciais na postura do professor. A primeira delas diz respeito à tomada de consciência em relação à identidade e aos interesses deste como “agente do conhecimento" (GERALDI, 1997, p. 121). Para o autor, as atividades desenvolvidas em sala de aula com a linguagem resultam de uma articulação entre concepções de mundo, de educação e de língua. E é como instrumento propiciador dessa consciência crítica que, como vimos, o trabalho com a pesquisa pode ser legitimado, a fim de proporcionar um despertar dos professores em relação ao seu objeto de ensino e às múltiplas instâncias nas quais estão inseridos.

Sobre as contribuições da pesquisa para a docência, Pimenta (2012) reafirma a potencialidade da prática investigativa como caminho para compreensão da atividade docente, de forma mais ampla, bem como dos processos de construção da identidade do professor, de sua profissionalidade, das condições de trabalho, de seu status e de suas possibilidades de liderança. Para a autora, assim como para Imbernón (2016, p. 194), a atividade de investigação por parte dos docentes precisa ocorrer, pois carrega a possibilidade de "refletir sobre o que se faz; unir a formação a um projeto de mudança nas escolas; realizar uma formação a partir de dentro (na escola); um processo orientado para decisões colaborativas; a necessidade de estabelecer pontes de comunicação entre os colegas”, sendo todos esses caminhos importantes para o exercício da profissão, de maneira mais ampla.

A compreensão dos professores como sujeitos críticos e capazes de refletir e de construir sua prática profissional, a partir de uma postura dialógica e problematizadora, contribui para uma nova relação com o saber e, consequentemente, aponta para o potencial de formação de sujeitos autônomos e conscientes de suas ações (CONTRERAS, 2002; TARDIF e MOSCOSO, 2018). 
Outra mudança na postura do professor de português diz respeito ao entendimento da linguagem como trabalho (GERALDI, 1997), como um fazer contínuo, cabendo ao docente proporcionar aos estudantes um contato efetivo com seus usos e possibilidades de realização, tendo em vista a pluralidade própria das interações sociais. Para isso, uma reformulação de concepções teóricas e de fazeres metodológicos sobre a língua e seu ensino torna-se essencial.

São muitas as contribuições dos estudos linguísticos para essa transição, tanto no tocante ao cabedal de conhecimentos produzidos em torno desse objeto, quanto no que diz respeito à formação dos professores. Segundo Geraldi (1996), a linguística e suas diferentes disciplinas oferecem subsídios importantes na compreensão da língua e de seu funcionamento. Além disso, a busca pela compreensão de alguns fenômenos, como a polifonia e a performatividade, por exemplo, fez com que os estudos linguísticos ampliassem suas fronteiras, permitindo um diálogo constante com outras áreas do saber, como a Filosofia, a Psicologia e a Sociologia.

A possibilidade do uso de diferentes ferramentas e áreas do conhecimento para entender os acontecimentos discursivos, as práticas de linguagem e os sujeitos que, ao mesmo tempo, as constituem e são constituídos por elas trouxe contribuições relevantes para a percepção da necessidade de transformação no ensino de língua materna ofertado nas salas de aula brasileiras. Já não se trata mais, segundo Geraldi (1996), de apreender uma língua para dela se apropriar, mas se trata de usá-la e, em usando-a, aprendê-la.

Geraldi (2018, p. 20) amplia essa discussão, ao afirmar que:

focalizar a linguagem a partir do processo interlocutivo e com este olhar pensar o processo educacional exige instaurá-lo sobre a singularidade dos sujeitos em contínua constituição e sobre a precariedade da própria temporalidade que o específico do momento implica. Trata-se de erigir a disponibilidade estrutural para a mudança em inspiração. E consequentemente destruir fronteiras determinadas entre educação sistemática e assistemática, já que sua manutenção implica em alijar da escola o próprio processo constitutivo de sujeitos e a linguagem vital, momentânea e própria com que de fato o indivíduo assume sua condição de sujeito (sujeito de discurso é aquele que tem com as condições de emergência de sua fala uma relação de pertinência) (GERALDI, 2018, p. 20) 
Assumir essa perspectiva, decorrente do avanço da incorporação dos estudos linguísticos ao ensino de língua materna, contribui para repensar as proposições existentes para a educação básica brasileira e as concepções subjacentes à prática do professor de linguagem, pois o acontecimento interlocutivo passa a ser encarado, segundo o autor, "em sua densidade, precariedade e singularidade, um estatuto diferenciado daquele de mero acidente de uso da expressão verbal, para tomá-la como fonte de produção da linguagem, dos sujeitos e do mundo discursivo" (p. 20), uma transformação na forma de concebê-los, portanto.

Ilari (1997), por sua vez, já afirmava que existem mais dois objetivos formativos igualmente importantes da incorporação da linguística nos cursos de Letras, e do desenvolvimento de pesquisas por parte desses futuros profissionais. Além de desautomatizar a visão corrente dos fatos da língua, essa aproximação proporciona ao futuro professor a oportunidade de praticar investigação a partir de métodos considerados científicos.

$\mathrm{Na}$ perspectiva da desautomatização da visão dos futuros professores de português sobre os fenômenos da língua, Ilari (1997) afirma que isso é possível, pois o docente em formação pode ser levado a "analisar fatos da Língua Portuguesa com rigor e sem preconceitos” (p. 15), fazendo uso, inclusive, de métodos científicos próprios das ciências para essa análise. Assim, muitos dos aspectos defendidos e normatizados pela gramática tradicional podem ser refutados pelo estudo científico, mostrando-se as limitações impostas por visões dogmatizadas da língua.

Ainda para Ilari (1997), a pesquisa proporcionada pela linguística no curso de Letras:

1 - introduz na formação do professor de Letras um elemento de participação ativa na análise da língua, que o habilitará a reagir de maneira crítica às opiniões correntes, e lhe permitirá, em sua vida profissional, avaliar com independência os recursos didáticos disponíveis e as observações e dificuldades de seus alunos;

2 - amplia as perspectivas a partir das quais a estrutura da língua pode ser observada; multiplica os horizontes do que se pode considerar curiosidade legítima acerca da língua e da competência para comunicar;

3 - proporciona-lhe uma vivência do método próprio das ciências naturais, envolvendo momentos de intuição e momentos de formalismo; empenha-o em formular e analisar hipóteses alternativas. A consequência previsível é a maior abertura para as outras áreas, o menor dogmatismo [...] (ILARI, 1997, p. 16-17). 
Apesar de assumir uma visão em certa medida limitada ao condicionar a pesquisa linguística ao rigor metodológico necessário às ciências naturais, mais próximas de um paradigma quantitativo de análise, Ilari (1997) destaca, no trecho acima, a relevância da pesquisa como instrumento capaz de despertar no docente de português em formação uma postura mais aberta em relação a seu objeto de ensino, o que lhe permite libertar-se de antigos dogmas normativos e debruçar-se sobre a língua em uso.

Hipoteticamente, a formação para ser também um pesquisador seria o caminho mais adequado para auxiliar o professor nesse caminho de mudança dos objetos e objetivos do ensino de língua materna, na medida em que pode oferecer, inclusive, a fundamentação teórica necessária para enfrentar os questionamentos e as turbulências próprias de um período de transição. Segundo Antunes (2003), o docente de língua portuguesa precisa assumir-se

como aquele que traça as linhas do caminho, as metas desejadas, como aquele que seleciona o objeto, os procedimentos e os recursos de trabalho. Evidentemente, com o respaldo das concepções teóricas, dos resultados das pesquisas linguísticas, da reflexão pedagógica cuidadosa, da atenção e do estudo diário [...] O professor de português precisa conquistar sua autonomia didática, assumir-se como especialista da área, comprometer-se com a causa da educação linguística de seus alunos. Não pode ficar, repito, à deriva, ao sabor das opiniões de todo mundo, como se não tivesse condições de estabelecer seus rumos (ANTUNES, 2003, p. 169-170).

A autonomia decorrente do domínio de saberes teóricos e da reflexão sobre a docência e sobre o conteúdo a ser ensinado aparece, na voz de Antunes, como importante elemento do trabalho do professor, visto que lhe permite uma maior maturidade e um maior conhecimento acerca de sua área de saber, contribuindo para a organização de seus instrumentos e práticas de ensino.

Concordamos também com Soares (2001), quando esta afirma que a pesquisa contribui, ainda, porque oferece ao professor não só o contato com o conhecimento, mas a possibilidade de, através da convivência e da vivência de atividades de investigação, "apreender e aprender os processos de produção de conhecimento em sua área específica" (p. 114), o que contribui para a sua compreensão do trabalho contínuo que envolve a construção e a produção de saberes. 
Apesar das múltiplas contribuições da pesquisa na formação de professores, as ações de investigação nos cursos de Letras ainda dependem, em sua maioria, da disponibilidade do professor formador, do tempo das aulas, do apoio institucional e de uma série de pré-requisitos para que sejam realizadas com a qualidade e o rigor metodológico esperados para um trabalho científico, o que muitas vezes dificulta e compromete a formação dos futuros professores para a pesquisa. Essa tarefa é, frequentemente, delegada aos cursos de formação continuada, principalmente em nível de pós-graduação stricto ou lato sensu, tornando a formação para a pesquisa restrita a uma minoria, se considerarmos o número de professores de português em atuação nas escolas brasileiras.

Mesmo reconhecendo as dificuldades de um processo ainda em implementação, reafirmamos a importância de construir e buscar a imagem do professor de língua portuguesa como pesquisador, visto que, além de importante caminho para melhoria da formação docente e da própria profissão, como vimos, ao pesquisar os diferentes fenômenos da língua e ao tomar conhecimento dos estudos linguísticos, o professor de português torna-se capaz de modificar e ampliar sua concepção de língua, percebendo as limitações estruturais e as contradições existentes em modelos de ensino mais tradicionais, baseados apenas na reprodução descontextualizada de regras da gramática normativa e, por conseguinte, limitados à variedade culta da língua (GERALDI, 1997; POSSENTI, 1996).

Essa tomada de consciência, advinda da crença em novas concepções e valores, impulsiona, segundo Travaglia (2004), a transformação nos currículos e nas práticas escolares, contribuindo para um ensino de língua voltado ao desenvolvimento de competências de leitura, de escrita e de reflexão sobre a língua e sua multiplicidade de usos e sujeitos.

\section{Considerações finais}

As pesquisas atuais na área de formação de professores revelam uma lacuna entre a necessidade aparentemente consensual de formar professores pesquisadores e a efetivação das práticas de pesquisa por parte desses profissionais, devido aos múltiplos e complexos fatores que estão relacionados à profissão e à formação 
docente. Em que pese a potencialidade da prática investigativa como elemento formativo e sua potencialidade para alterar o status e o exercício da docência, desde a educação básica, inúmeras são as dificuldades para o seu desenvolvimento nesse nível da educação nacional.

O desenvolvimento de práticas de pesquisa exige grande comprometimento do pesquisador, e, quando do exercício da profissão docente, essas práticas estão condicionadas também a questões relacionadas à formação e a elementos como, por exemplo, as condições de trabalho (DINIZ-PEREIRA, 2011 e FALCÃO, 2013). Dessa forma, aspectos relacionados às condições do exercício profissional, com jornada, carreira e valorização compatíveis com o esperado da profissão, precisam ser observadas, tornando imperiosos o respeito ao Plano Nacional de Educação e a efetivação das metas e dos dispositivos legais atinentes à sua implementação.

Considerando o atual momento de transição no ensino de língua, o qual exige do docente uma reflexão aprofundada acerca de suas concepções ideológicas e a busca por novas alternativas teórico-metodológicas para o processo de ensinoaprendizagem, acreditamos que a prática investigativa pode emergir como uma das alternativas possíveis para contribuir com as transformações necessárias a essa reconfiguração.

A importância do trabalho investigativo para o professor de português fundamenta-se, pois, na crença dessa prática como alternativa na consolidação desse novo modelo de ensino, visto que, além de benefícios para a formação e o exercício da docência, de forma mais ampla, pode trazer uma maior autonomia ao professor no interior do processo de ensino-aprendizagem da língua, desde o momento de redefinição dos conteúdos até o desenvolvimento de competências que colaboram para a efetiva ampliação da inserção do alunado nas práticas sociais de leitura e escrita (MENDONÇA, 2006).

A atividade de pesquisa mostra-se, portanto, dotada de potencial para contribuir tanto com o reconhecimento social do professor como profissional crítico reflexivo, que compreende e faz uso de diferentes instrumentos e processos de produção de conhecimento, como para o desenvolvimento desse profissional frente à compreensão dos fenômenos relativos ao seu próprio objeto de estudo, no 
contexto da reconstrução de saberes e práticas anteriormente consolidados no exercício de sua profissão.

\section{Referências}

ANDRÉ, M. (org.). O papel da pesquisa na formação e na prática dos professores. Campinas: Papirus, 2001.

ANTUNES, I. Aula de Português: encontro e interação. São Paulo: Parábola Editorial, 2003.

ANTUNES, I. Muito além da gramática: por um ensino de línguas sem pedras no caminho. São Paulo: Parábola Editorial, 2007.

BRASIL/CNE. Diretrizes Curriculares Nacionais para a formação de professores da educação básica, em nível superior, curso de licenciatura, de graduação plena. Parecer $\mathrm{CNE} / \mathrm{CP} / 009 / 2001$.

BRASIL. Ministério da Educação. Conselho Nacional de Educação. Resolução CNE/CP $\mathrm{n}^{\mathrm{o}}$ 1, de 18 de fevereiro de 2002. Define as Diretrizes Curriculares Nacionais para a Formação de Professores da Educação Básica, em nível superior, curso de licenciatura, de graduação plena. Brasília, DF: MEC/CNE, 2002.

BRASIL. Lei no 13.005, de 24 de junho de 2014. Aprova o Plano Nacional de Educação PNE e dá outras providências. Disponível em <http://www.planalto.gov.br/ccivil_03/_ato2011-2014/2014/lei/113005.htm>.

BRASIL. Ministério da Educação. Conselho Nacional de Educação. Resolução CNE/CP n. 2, de 1 julho de 2015. Define as Diretrizes Curriculares Nacionais para a formação inicial em nível superior (cursos de licenciatura, cursos de formação pedagógica para graduados e cursos de segunda licenciatura) e para a formação continuada. Brasilia, DF: MEC/CNE, 2015.

BEILLEROT, J. A "pesquisa": esboço de uma análise. In: ANDRÉ, M. (org.). O papel da pesquisa na formação e na prática dos professores. Campinas: Papirus, 2001.

CONTRERAS, J. A autonomia de professores. São Paulo: Cortez, 2002.

DINIZ-PEREIRA, J \& ZEICHNER, K. (org.). A pesquisa na formação e no trabalho docente. Belo Horizonte: Autêntica Editora, 2011.

DINIZ-PEREIRA, J. A pesquisa dos educadores como estratégia para construção de modelos críticos de formação docente. In: DINIZ-PEREIRA, J \& ZEICHNER, K.(org.). A pesquisa na formação e no trabalho docente. Belo Horizonte: Autêntica Editora, 2011.

DORNELLES, C. A gente não quer tradicional, mas...como é que faz daí? Conservadorismo e inovação na formação de professores de português como língua materna. In: SIGNORINI, I. Significados da inovação no ensino de língua portuguesa e na formação de professores. Campinas: Mercado de Letras, 2007. 
DOURADO, L. Valorização dos profissionais da educação Desafios para garantir conquistas da democracia. Revista Retratos da Escola, Brasilia, v. 10, n. 18, p. 37-56, jan./jun. 2016. Disponível em: $<$ http://retratosdaescola.emnuvens.com.br/rde/article/viewFile/649/671>. Acesso em: 29 jan. 2019.

FALCÃO, G. O professorpesquisador em Pernambuco: concepções e experiências de professores de português das escolas de referência em ensino médio. Dissertação (Mestrado em Educação) - Programa de Pós-Graduação em Educação, Universidade Federal de Pernambuco, Recife, 2013.

GATTI, B. Didática e formação de professores: provocações. Cadernos de Pesquisa, v. 47, n. 166. p. 1150-1164, out./dez. 2017. Disponível em: $<$ http://publicacoes.fcc.org.br/ojs/index.php/cp/article/view/4349/pdf>. Acesso em: 29 jan. 2019.

GERALDI, J. W. Linguagem e Ensino. Campinas: Mercado das Letras, 1996.

GERALDI, J. W. Portos de passagem. São Paulo: Martins Fontes, 1997.

GERALDI, J. W. Educação e linguagem. In: SILVA, E., SILVA, L. e OLIVEIRA, L. Palavras andantes: ensino de leitura - antologia comemorativa. Campinas: Edições Leitura Crítica/ALB, 2018.

ILARI, R. A linguística e o ensino da língua portuguesa. São Paulo: Martins Fontes, 1997.

IMBERNON, F. Qualidade do ensino e formação do professorado: uma mudança necessária. São Paulo: Cortez, 2016.

LÜDKE, M.; ANDRÉ, M. Pesquisa em Educação: Abordagens Qualitativas. São Paulo: EPU, 1986.

LÜDKE, M. O professor da escola básica e a pesquisa. In: CANDAU, V. (org.). Reinventar a escola. Petrópolis: Vozes, 2000.

LÜDKE, M. O professor e a pesquisa. Campinas: Papirus, 2001.

MENDONÇA, M. Análise linguística no ensino médio: um novo olhar, um outro objeto. In: BUNZEN, C. \& MENDONÇA, M. (Org.). Português no ensino médio e formação do professor. 1. ed. São Paulo: Parábola, 2006.

PERRENOUD, P. Dez novas competências para ensinar. Porto Alegre: Artes Médicas Sul, 2000.

PERRENOUD, P. A prática reflexiva no oficio de professor: profissionalização e razão pedagógica. Porto Alegre: Artmed editora, 2001.

PIETRI, E. A constituição do discurso da mudança no ensino de língua materna no Brasil. Tese (Doutorado em Linguística Aplicada) - Instituto de Estudos da Linguagem, Unicamp, Campinas, 2003.

PIMENTA, S. Professor reflexivo: construindo uma crítica. In: PIMENTA, S. e GHEDIN, E. (Orgs.). Professor reflexivo no Brasil: gênese e crítica de um conceito. São Paulo: Cortez, 2012.

POSSENTI, S. Por que (não) ensinar gramática na escola. Campinas: Mercado das Letras, 1996. 
SANTOS, L. Dilemas e perspectivas na relação entre ensino e pesquisa. In: ANDRÉ, M. (org.). O papel da pesquisa na formação e na prática dos professores. Campinas: Papirus, 2001.

SCHNETZLER, R. Prefácio. In: GERALDI, C.M.G. \& et al. (org.). Cartografias do trabalho docente. Professor(a) pesquisador(a). Campinas: Mercado de Letras/ALB, 1998.

SCHÖN, D. Formar professores como profissionais reflexivos. In: NÓVOA, A. (org.) Os professores e sua formação. Lisboa: Dom Quixote, 1992.

SHAVININA, L. (org.) The international handbook on innovation. Londres: Pergamon, 2003.

SOARES, M. As pesquisas nas áreas específicas influenciando o curso de formação de professores. In: O papel da pesquisa na formação e na prática dos professores. Campinas: Papirus, 2001.

SUASSUNA, L. Ensaios de pedagogia da lingua portuguesa. Recife: EDUFPE, 2006.

TARDIF, M. \& MOSCOSO, J. A noção de "profissional reflexivo" na educação: atualidade, usos e limites. Cadernos de pesquisa, v. 48 n. 168 p. 388-411 abr./jun. 2018. Disponível

em: < http://publicacoes.fcc.org.br/ojs/index.php/cp/article/view/5271/pdf>. Acesso em: 29 jan. 2019.

TRAVAGLIA, L. C. Gramática: ensino plural. 2. ed. São Paulo: Cortez, 2004. 